Journal of Environmental Science and Public Health

doi: $10.26502 /$ jesph. 96120055

fortune

Volume 3, Issue 2

Review Article

\title{
A Novel Introduction of Municipal Solid Waste Management
}

\author{
Sylvia Adipah ${ }^{1 *}$, Ofotsu Nana Kwame ${ }^{2}$ \\ ${ }^{1}$ Department of Environmental Engineering and Science, Chongqing University, Chongqing, China \\ ${ }^{2}$ Department of Mechanical Engineering, Chongqing University, Chongqing, China \\ "Corresponding Author: Sylvia Adipah, Department of Environmental Engineering and Science, Chongqing \\ University, Chongqing 400044, China, E-mail: fransil351@yahoo.com
}

Received: 21 December 2018; Accepted: 20 March 2019; Published: 02 April 2019

\begin{abstract}
Managing solid waste is problem facing worldwide. In developing counties rapid increase of solid waste is produced as a result of rapid population increases, urbanization, rapid industrialization and economic sustainability. The challenges in urban areas are diverse and enormous in a global point of view, but looking at the developing countries, particularly in the cities, an inadequate waste collection and its inefficient management systems are the causes of serious urban pollution and risks to public health and environment, affecting the population, expressly the poor ones [1]. The research process will focus on sustainable development and integrated solid waste management theories.
\end{abstract}

Keywords: Municipal solid waste management; Sustainable development; Pollution

\section{Introduction}

\subsection{Overview}

Waste is a complex mixture of different substances that are discarded by household, individual or organizations that are harmful to the environments and health [2]. Waste management consists of collection, processing, transport and disposal of solid waste. Rapid populations cause increases of municipal solid waste in developing countries, economy, urbanization and high-level living standards of an individual or community [3]. Municipal authorities are responsible for waste management in the municipalities; they implement measures to ensure an effective and efficient way to manage solid waste, facing challenges that are beyond them to tackle [4]. Currently, the world 
generates around 3.5 million tons of waste per day or 1.3 billion tons per year among which $54.02 \%$ come from developing countries [5]. The more wastes created, the more area is required for disposal. This problem in turn affects the environment and the health of ecosystems and biodiversity.

\subsection{Municipal solid waste management in some countries of the world}

Municipal solid waste management (MSWM) has been undertaken with many drivers worldwide over the years. The principal objectives of MSWM were gradually developed to protect environmental issues, health safety, and resource conservation [6]. Challenges of MSWM as a result rapid generation of waste due to population growth, lifestyles of people, development and consumption of less biodegradable products. Distinct differences have been identified in literature between MSWM in developed and developing countries. In most developed countries, public health is no more a major driver of waste management; the current focus is on optimization of waste management practices with a broader goal of resource conservation [6, 7]. In developed or developing countries waste management have its challenges, as developing countries waste management will be achieve focusing on economic, population growth and environmental issues. This is important owing to the fact that the more the environment is degraded in a particular region, the greater the effort that will be required to restore its quality [8].

Waste management in Europe is highly diverse. Main disposal technologies and recycling and recovery rates are different. France, Netherlands, Germany, Denmark, Belgium, Luxembourg and Sweden traditionally rely on incineration for waste management. UK, Portugal, Spain and Greece landfill nearly all their MSW. Most newcomers in the EU also landfill their MSW. In the Central and Eastern European Countries however, the amount and the kind of MSW collected are different because of their different economic situation. Growing economy has led to rapid population growth with a corresponding increase in solid waste generation. Latin American generates about 369,000 tons a day of municipal solid waste, 56 percent of it in large urban centres, 21 percent in medium-size ones, and 23 percent in small ones. The total per capita rate of waste generation is about $0.8 \mathrm{~kg} / \mathrm{p}$, though it can exceed $2.4 \mathrm{~kg} / \mathrm{p}$ during peak tourism seasons in some municipalities [9].

As for developing countries the main similar pattern related to the MSWM refers to ineffective planning, technical no how, lack of scientific research and improper management system. Moreover, there are cases of insufficient public and private funds and corrupt public sanitation management systems. There also exist groups, many of whom live at the disposal sites, who make their daily living by separating and selling the solid wastes and who frequently consume those wastes as part of their diet [10]. In Africa, only $31 \%$ of solid waste is collected in urban areas and due to an inadequate urban infrastructure, large part of the wastes are not treated, collected and disposed appropriately. In Accra, for example, although there is a system for collecting waste in predetermined locations, in most residential areas the collection is done irregularly which causes the overflowing of illegal landfills. The average waste generation rate in Abuja is $0.55-0.58 \mathrm{~kg}$ per person per day. Illegal disposal is also common in Abuja. Piles of solid wastes are often found along roads, underneath bridges, in culverts and drainage channels and in other open spaces [11]. It is clear that there is a great gap between developed and developing countries in the MSWM 
standards, but differences among developing countries also exist. MSWM systems in different developing countries can vary substantially and in some cases are virtually non-existent [12].

\section{Literature Review of Solid Waste Management}

\subsection{Concepts in waste management}

Much has been written about the waste problem yet the definition of the term waste is quite rare in the scholarly literature on the topic. According to Gilpin waste is an unwanted and economically unusable by products or residuals at any given place and time, and any discarded materials into the environment" [13]. Davies also describes wastes as: "unwanted or unusable materials from industry and agriculture, businesses and other households items and can be liquid, solid or gaseous in nature, and hazardous or non-hazardous [14]. The attribute of waste can be compared with the concept of 'resource', which has also been defined as material that has use-value, and "a reflection of human appraisal" [15]. Jessen also noted "our waste stream is actually full of resources going in the wrong direction" [16].

\subsection{The classification of waste}

Waste can be classified into categories, thus sources, material composition and the level of risk associated with waste substances that is associated with appropriate waste management practice. Classifying waste is essential to aid in waste management planning, it helps municipal authorities to organize waste management operation such as

collection, and waste disposal methods. Over the years waste management have been improved in developed countries [17].

\subsection{The goals of waste management}

In 1976, the United States Congress implemented a law regarding the Resource Conservation and Recovery Act (RCRA), which authorized the EPA to regulate waste management and disposal practices. The goals of waste management that were set by the RCRA included

1. Preventing hazardous waste disposal against human health and the environment

2. Using recycling and recovery to protect energy and natural resources

3. Creating zero waste solid waste management

4. Environmental management of solid waste [18].

To achieve the goals of municipal solid waste management, it is necessary to establish sustainable systems of solid waste management, which will meet the needs of the entire urban population including the poor and by preventing the pollution of the natural environment and its resources such as land, water, and air as well as the aesthetic environment. 


\subsection{The principles of waste management}

The principles of waste management are to minimize waste generation, maximize waste recycling and reuse to ensure environmental sustainability. Cointreau created measures to developed sustainable and integrated solid waste management programme.

1. Supportive of good governance.

2. Provide economic service delivery.

3. Long-term financial sustainability.

4. Conserve natural resources.

5. Embrace public participation.

6. Foster environmentally appropriate technologies and sites.

7. Seek appropriate levels of source segregation, recycling and resource recovery.

8. Conduct strategic facility planning and development.

9. Build institutional capacity.

10. Invite private sector involvement [19].

\section{Integrated Waste Management and the Waste Hierarchy}

Waste prevention and reduction are placed at the top to show that the best way to deal with waste is to prevent its production and, where this is not possible, to produce less of it. At the other extreme, disposal is placed at the bottom to show that it should be the last resort among the strategies for waste management. In spite of efforts by municipal authorities to improve waste management, most countries in the world still resort to strategies at the bottom of the waste hierarchy. Other instruments that encourage good practice in waste management are the proximity principle (PP) and the best practicable environmental option (BPEO). The proximity principles call for the disposal of waste as close to its source as possible. Among other advantages, this practice reduces the time, energy and expenses involved in the transportation of waste to disposal sites, and also minimize the possibility of accidents associated with the transportation of waste. With regard to the BPEO, it encourages the use of waste management strategies that achieve the most benefits in terms of cost, energy and time, and that also cause the least damage to the environment.

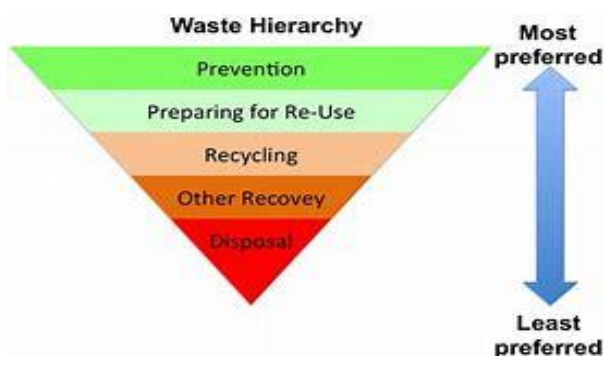

Figure 1: The Waste Hierarchy. 


\subsection{Sustainable waste management}

To ensure the protection of human health, environment and scarcity of resources of the earth, sustainable waste management must be regarded as an approach to waste management for future generation. It therefore becomes important to minimize natural resource extraction and consumption by recycling waste materials, and conduct waste management efficiently to curtail the environmental impacts of waste disposal [20]. The waste hierarchy is best way to achieve sustainable waste management to reduce the amounts of waste produce. Reuse and recycling as a sustainable approach must be encouraged. Finally, where waste prevention/reduction, re-use and recycling are economically impossible, waste is processed to recover their intrinsic values such as energy. Sustainable waste management also seeks to increase co-ordination between the producers of goods, retailers, manufacturers and the concerns of the public, governments or local authorities with waste management [21]. Moreover, recent proposals for improving waste management in many rich countries called for more incineration rather than recycling [22] which are just one step up from land filling at the bottom of the waste hierarchy.

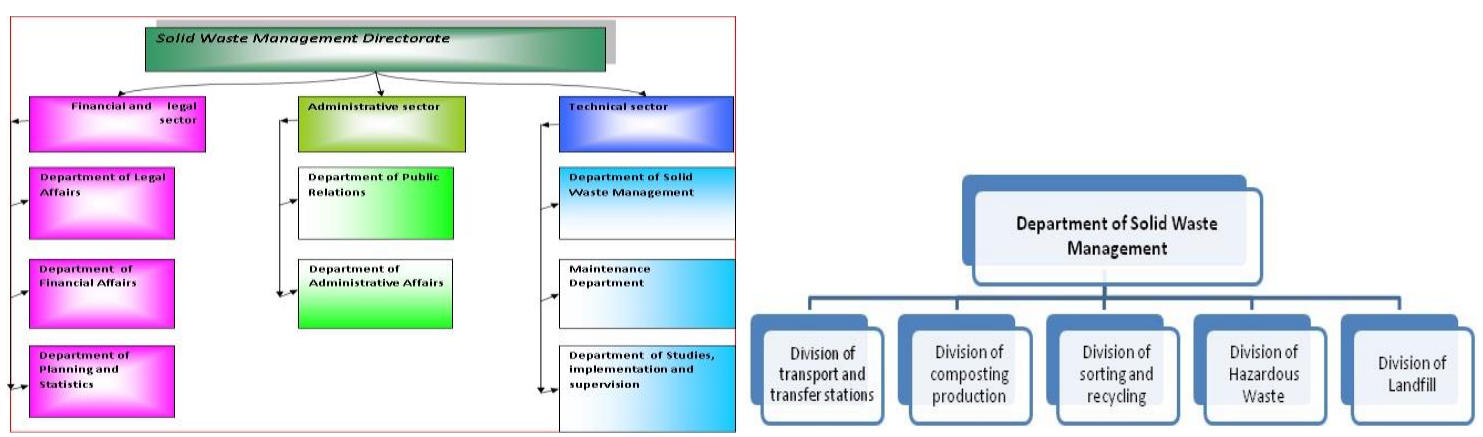

Figure 2: Solid Waste Management and Organization.

\section{The Urban Solid Waste Problem in Developing Countries}

\subsection{The nature of the problem}

In developing countries where solid waste management is still an emerging issue, UNEP researchers focuses on matters regarding MSWM and its effect on human health and the environment. In these developing countries they are battling with other arising matter like hunger, health problems, water shortages, unemployment and civil war, therefore understanding the reasons of waste problems have to grow steadily [23]. In developing countries solid waste management have become an issue of concern to health risk due to uncontrolled landfills causing contamination to drinking water and soil. To improve the system of waste management there should be legal framework guiding it, collection and disposal are one main key principle. Infrastructure and detailed of waste data must be put in place.

Pointed out way forward strategies are: 1) Foster effective cooperation, information sharing and knowledge transfer between the public and private sectors; 2) Develop facilities, support services and enforcement capabilities 
simultaneously with the necessary legislation and regulations; and 3) Build up of controlled landfills (a high priority in these countries). "Polluter pays" concept must be implemented by introducing cost recovery systems.

In addition, is believed that much can be achieved by small-scale improvements in the existing systems, and also the need to build strong relations among developing countries to encourage solid waste management [24]. Buenrostro and Bocco, looked at the causes and implications which determine some solid wastes (SW) patterns in developing countries using Mexico as a study case-specifically it is an analysis of the current state of SW production and the goals and perspectives regarding the social, economical, technical and environmental implications for Mexico. Similarities among SW composition, it is also a common feature in developing countries. Developing societies acknowledge the importance of modernize the existent SW management system by implementing solid waste reuse and recycle programs, as well as, adopt suitable treatment systems to counteract environmental problems.

A review of China's overall situation of MSWM and several ideas for improvement can be found in Zhang, Tan and Gersberg, work. Chinese population has increased over the past two decades and its economy has developed tremendously with respect to recycling of solid waste, technologies and developmental strategies. Landfilling is the predominant method of disposal of MSW at the present. Although most of waste generated in China is landfilled, in some cities, the landfills quite resemble open dumps, which unfortunately can be detrimental to the urban environment and allowing landfill leachate treatment practice. Improving MSWM in China can be achieved by various financial mechanisms. In the future, all stakeholders should be encouraged to participate in the decisionmaking process concerning MSWM. Currently, there is no limitation on the amount of residential solid waste generated, and the convenience of waste disposal is responsible for more solid waste generation.

\subsection{Causes of the solid waste problem in developing countries}

Factors that mitigates solid waste management as a successful tool are

1. Inappropriate technologies/processes.

2. Enforcement inefficiencies/non-existent; illegal dumping.

3. Lack of financing.

4. Lack of training/human resource.

5. Lack of political support.

6. Lack of legislation.

7. Policy conflict among levels of government/overlapping responsibilities.

8. Rapid increase in waste generation/limited data.

9. Lack of awareness among public.

10. Limited land areas; land tenure issues [25]. 


\section{Theoretical Framework of Solid Waste Management}

It is becoming widely recognized that an integrated approach to waste management leads to the sustainability of the solid waste management system.

\subsection{MSWM authorities}

MSWM authorities are the stakeholders or people or organizations that may have an interest in adequate waste management. The major missions of MSWM authorities are to create a proper legislation, adequate policies and strong regulation, put and support strategic plans (encouragement, monitoring and implementation); to get efficiency and adequacy management Procedures, the need to gather accurate data on such topics as the quantities and types of waste being generated in the cities and massive investment in equipment and logistics for waste management operations is also part of the authority's responsibilities, as well as responsible to Build up a system in which the communication and information flow among all system stakeholders efficiently work, especially for the major MSW generators, by massive publicizing the existent rules and guidelines to be followed and creating more interaction opportunities between the authorities, generators and other major stakeholders.

\subsection{MSW stream, infrastructures and processes}

A MSWM system must be supplied with infrastructures and equipment, quantitatively and qualitatively, and Improvements to technical systems are required at the levels of collection (container and vehicle specification, vehicle routing, vehicle maintenance), transfer (primary to secondary transfer points, large transfer stations), recovery (composting, sorting facilities and organisation) and final disposal (sanitary landfills, energy recovery from landfill gas), as well as try to find local solutions and enhance and strengthen the Cooperation with private sector. The waste generators must be participating in the decision making process in terms of infrastructures, equipment and applied technologies for waste management, so that they can make full and better use of these resources.

\subsection{Waste generators-household generators}

Waste generators largely influence the way MSWM system is designed; their behaviour and willingness may guide management decisions including, for example, refuse fee establishment, waste reduction, separation and waste recycling policies. In addition, generators behaviour depends on their awareness and participation level concerning MSWM matters. Furthermore, the existence of a good and well-built relationship between waste generators, the MSWM authorities and service providers is a success indicator when it comes to analyse the performance of a MSWM system.

\subsection{Methods of data generation}

5.4.1 Document review: The analysis of documents is yet important source of data for science research. Documents are a good place to search for answers and they provide a useful check on primary information gathered through interviews and questionnaires. Furthermore, documentary sources can provide a convincing answer when other techniques fail to resolve a question. Part of the information for this study was obtained from both the traditional 
documentary sources like reports and newspaper articles as well as from electronic media sources including television and radio programmes.

5.4.2 Interviews: Interviewing is a useful way of collecting qualitative data because the technique is 'introspective' and allows respondents to report on themselves, their views, their beliefs, practices, interactions and concerns [26]. The interview technique is associated with a number of advantages over questionnaires Interview creates the opportunity for interviewers to ask for clarification when they do not understand a question just as the interviewer can ask for elaborations on answers given by interviewees. Furthermore, there is the guarantee that all questions would be answered or, at least, attempted by the interviewee which ensures a high response rate.

Moreover, it becomes possible to check on the reliability of a response by asking the same question differently and at different stages of the interview [26]. The interview technique used to obtain data from a number of stakeholder include:

1. Officials of the municipal waste departments

2. Private waste companies and informal waste collectors

3. Residents of communities residing around waste disposal facilities.

5.4.3 Public questionnaires in Accra, Ghana: The questionnaire is one of the most widely used instruments for collecting data in survey research. The survey questionnaire also enables one to collect standardised information in respect of the same variables for everyone in the sample selected [27]. This makes the questionnaire an indispensable tool in gathering primary data about people, their behaviour, attitudes, opinions and awareness of specific issues. Questionnaire for household survey covers issues concerning waste generation and disposal practices, availability and type of waste management services, payments for waste management services, and householders' perceptions about the waste situations in their communities and how the situation could be improved [28-35].

\section{Discussion}

Integrated Solid Waste Management (ISWM) it is an answer to address solid waste management issues, since all aspects of a solid waste management system-technical and non-technical are analysed together in order to provide waste management practices as environmentally sound as possible. In addition, a flexible policy tool that is a foundation ISWM-waste management hierarchy-supply the ranks for waste management options in order of sustainability, from the most preferred option to the least ideal option (waste generation, treatment, and disposal), taking carefully in account financial, social, and environmental considerations. Developing countries still have a long way to go concerning MSWM matters, as economic and social constraints figure as the main reason for the low priority given to their MSWM systems. Address the current situation requires a phased intervention in the technical and legal framework with the aim to improve the system in a continuous way [36-40]. Furthermore, it is important to consider the significance of inner cooperation among developing countries, to exchange experiences and 
information to upgrade their systems [41-48].

\section{Conclusions}

From the literature review, it is possible to enumerate the main points guiding this study work. Nowadays societies long for sustainability, and sustainable development it is a well recognised approach to achieve this goal, because the ultimate objective is to provide well being for the present and future generations. Sustainable development contribution to the management of municipal solid waste it is a combination of the cities' needs and the aspects including waste reduction, recovery and proper treatment; waste management authorities work performance and financial sustainability; and public acceptance concerning the waste managing practices.

\section{References}

1. United Nations Environment Programme (UNEP). Principles of solid waste management. Solid Waste Management (2005): 1-8.

2. Rushton L. Health hazards and waste management. British Medical Bulletin 68 (2003): 183-197.

3. Minghua Z, Xiumin F, Rovetta A, et al. Municipal solid waste management in Pudong New Area, China (2009).

4. Sujauddin M, Huda MS, Rafiqul Hoque ATM. Household solid waste characteristics and management in Chittagong, Bangladesh. Journal of Waste Management 28 (2008): 1688-1695.

5. Hoornweg D, Bhada-Tata P. A Global Review of Solid Waste Management. What a Waste (2012).

6. McDougall F, White P, Franke M, et al. Integrated Waste Management: A Life Cycle Inventory, $\left(2^{\text {nd }}\right.$ Edn. $)$. Blackwell Science, Oxford, UK (2001).

7. Wilson DC. Development drivers for waste management. Waste Management and Research 25 (2007): 198-207.

8. United Nations Environment Programme. Regional Office for West Asia (ROWA) (2005).

9. Pan American Health Organization. Report on the Regional Evaluation of Municipal Solid Waste Management Services in Latin America and the Caribbean. Area of Sustainable Development and Environmental Health, PAHO, Washington, DC (2005).

10. Buenrostro O, Bocco G. Solid waste management in municipalities in Mexico: goals and perspectives. Resources Conservation \& Recycling 39 (2003): 251-263.

11. Solid Waste Audit Report. Federal Capital Territory, Abuja (2004).

12. United Nations Environmental Programme. Waste Management Planning: An Environmentally Sound Approach for Sustainable Urban Waste Management. GDRC (2005).

13. Gilpin A. Dictionary of Environment and Development. Chester and New York, John Wiley and Sons (1996).

14. Davies AR. The Geographies of Garbage Governance: Interventions, Interactions and Outcomes. London (2008). 
15. Jones G, Hollier G. Resources, Society and Environmental Management. London, Paul Chapman Publishing Ltd (1977).

16. Jessen M. Zero Waste Services. Kutenai Marketing Group (2002).

17. Hardoy JE, Mitlin D, Satterthwaite D. Environmental Problems in an Urbanizing World, London and Stirling, VA (2001).

18. Resource Conservation and Recovery Act. Introduction to the RCRA (1976).

19. Cointreau S. Declaration of Principles for Sustainable and Integrated Solid Waste Management (2001).

20. Millennium Assessment Report. Living Beyond Our Means: Natural Assets and Human Well-being (Statement of the MA Board) (2005).

21. London Waste Action. Promoting Sustainable Waste Management in London (2007).

22. Chazan D. A World Drowning in Litter, BBC. Full Text Data Base. BBC (2002).

23. Patrick AB, Aliata IM. Urban Solid Waste Management in Ghana: an Assessment of Zoomlion's Approach to Waste Management in the Wa Municipality. Journal of Environment and Earth Science 3 (2013).

24. United Nations Programme for Environmental Protection. Integrated Waste Management Scoreboard-A tool to measure performance in municipal solid waste management (2005).

25. Linden O, Gomez ED, Ngoilie MAK. Common Constraints to Waste Management Programs on the East Asian Seas Region: Top Ten Constraints. GEF/UNDP/IMO Regional Programme (1997).

26. Freebody P. Qualitative Research in Education: Interaction and Practice. London (2003).

27. Zahari RK. Urban Environmental Hazards: A Case Study of Flood Hazards in Kuala Lumpur, Malaysia. Unpublished PhD Thesis Submitted to the University of Nottingham (2007).

28. Al-Yousfi AB. Environmentally Sound Technologies (EST) for Designing and Operating Solid Wastes Landfills. Proceedings of International Conference on Wastes Management and Pests Control, Muscat Municipality-Oman (2003).

29. Diaz LF, Savage GM, Eggerth LL. Overview of Solid Waste Management in Economically Developing Countries. In: Proceedings of Organic Recovery and Biological Treatment, ORBIT 99, Part 3, Rhombos, Berlin (1999): 759-765.

30. Durham County Council. Sustainable Waste Management (2007).

31. Gebreegziabher Z, Hagos D, Mekonnen A. Household's willingness to pay for improved solid waste management: The case of Mekelle City, Ethiopia (2010).

32. Kanbour F. General Status on Urban Waste Management in West Asia, Regional Workshop (2010).

33. METAP. Proceedings of the Regional Workshop, Regional Solid Waste Management Project in the Mashreq and Maghreb Countries, Amman, Jordan (2005).

34. METAP. Development of Strategic Framework for Private Sector Participation in MSW Management report. Jordan, Ministry of Environment (2008).

35. National profiles for Brunei, Darussalam, Cambodia, China, Indonesia, Japan, Malaysia, Philippines, Singapore, Thailand and Vietnam. 
36. Rhyner CR, Schwartz LJ, Wenger RB, et al. Waste Management and Resource Recovery, ( $1^{\text {st }}$ Edn.). CRC Press (1995).

37. Schubeller P, Wehrle K, Christen J. Urban Management and Infrastructure (1996).

38. Conceptual Framework for Municipal Solid Waste Management in Low-Income Countries. Working Paper No. 9. UNDP/UNCHS (Habitat/World Bank/SDC Collaborative Programme on Municipal Solid Waste Management in Low Income Countries. St, Gallen, SKAT.

39. Seadon JK. Integrated waste management-Looking beyond the solid waste horizon. Waste Management 26 (2006): 1327-1336.

40. Seadon JK. Sustainable waste management systems. Cleaner Production 18 (2010): 1639-1651.

41. Shekdar AV. Sustainable solid waste management: an integrated approach for Asian countries. Waste Management 29 (2009): 1438-1448.

42. Suocheng D, Tong KW, Yuping Y. Municipal solid waste managemen in China: Using commercial management to solve a growing problem. Utilities Policy 10 (2001): 7-11.

43. Tchobanoglous G, Theisen H, Vigil SA. Integrated Solid Waste Management: engineering principles and management issues (1993).

44. United States Environmental Protection Agency. Office of Solid Waste (5306P) (2008).

45. WCED. Our Common Future (The Brundtland Report)-Report of the World Commission on Environment and Development. Oxford, Oxford University Press (1987).

46. World Bank. What a Waste! Solid Waste Management in Asia. Urban Development Sector Unit. East Asia and Pacific Region (1999).

47. Zhang B, Keat TS, Gersberg RM. Municipal solid waste management in China: Status, problems and challenges. Environmental Management 91 (2010): 1623-1633.

48. Zurbrugg C, Schertenleib R. Main problems and issues of municipal solid waste management in developing countries with emphasis on problems related to disposal by landfill. Third Swedish Landfill Symposia, Sweden (1998).

Citation: Sylvia Adipah, Ofotsu Nana Kwame. A Novel Introduction of Municipal Solid Waste Management. Journal of Environmental Science and Public Health 3 (2019): 147-157.

This article is an open access article distributed under the terms and conditions of the Creative Commons Attribution (CC-BY) license 4.0 